\title{
A PROSPECTIVE STUDY OF VARIOUS METHODS OF MANAGEMENT OF DISTAL RADIUS FRACTURES
}

\author{
Sankara Rao Pinnamaneni ${ }^{1}$, Suresh Padya ${ }^{2}$, P.T.V. Kiran Kumar ${ }^{3}$
}

${ }^{1}$ Associate Professor, Department of Orthopaedics, Maharaja's Institute of Medical Sciences, Nellimarla, Vizianagaram. ${ }^{2}$ Assistant Professor, Department of Orthopaedics, Maharaja's Institute of Medical Sciences, Nellimarla, Vizianagaram. ${ }_{3}^{3}$ Postgraduate, Department of Orthopaedics, Maharaja's Institute of Medical Sciences, Nellimarla, Vizianagaram.

\section{ABSTRACT}

\section{BACKGROUND}

The term distal end radius refer to fractures beginning at proximal end of pronator quadratus and ending at the radiocarpal articulation. Various treatment modalities has been described, but every procedure has its own pros and cons.

\section{MATERIALS AND METHODS}

A prospective study conducted on sixty adult patients with distal radial fractures treated at Chalmeda Anand Rao Institute of Medical Sciences, Karimnagar, between May 2013 and August 2015.

\section{RESULTS}

There were $42(70 \%)$ males and 18 (30\%) females between the age group of 22-60 years; 40 (66.6\%) patients had right side involvement (Dominant wrist) and $20(33.3 \%)$ had left side involvement. Of the 60 selected cases closed reduction cast application done in 30 cases. Closed reduction external fixation in 2 cases. Closed reduction with $\mathrm{K}$-wire fixation in 5 cases, Open reduction and Internal fixation with plating in 12 cases and closed reduction and external fixation and K-wires 3 cases, open reduction and plating and $\mathrm{K}$ wires in 8 cases.

\section{CONCLUSIONS}

The choice of particular operative method for each case should depend on fracture pattern, reducibility, stability quality of bone and patient requirement.

\section{KEYWORDS}

Distal Radius Fractures, Various Treatment Methods, Results.

HOW TO CITE THIS ARTICLE: Pinnamaneni SR, Padya S, Kumar PTVK. A prospective study of various methods of management of distal radius fractures. J. Evolution Med. Dent. Sci. 2016;5(77):5755-5758, DOI: 10.14260/jemds/2016/1297

\section{INTRODUCTION}

The term fractures of distal end radius refer to fractures beginning at the proximal end of pronator quadratus and ending at the radiocarpal articulation. ${ }^{1,2}$ Distal radius fractures were often considered primarily stable extra-articular fractures and articular injuries that disrupt both the radiocarpal and distal radio-ulnar joints. ${ }^{3}$ Without approach to managing intra-articular fractures of the radius. The radial column consists of the scaphoid fossa and the radial styloid. The intermediate column consists of the lunate fossa and the sigmoid notch of the radius. The ulnar column consists of the ulnar styloid, but also should include the TFCC and the ulnocarpal ligaments.
\end{abstract} supplemental skeletal fixation, re-displacement can occur. Resultant malunion leads to pain, limited range of motion, weakness and post-traumatic arthritis. ${ }^{4}$ Various treatment modalities has been described, but each technique has its own pros and cons.5,6,7 Results of the currently published data are difficult to compare and most of the studies are retrospective in nature and use various classifications and inconsistent tools, especially in regard to comminuted fractures with joint incongruity. ${ }^{8}$ Among various factors including the radiographic fracture pattern, quality of bone, fracture displacement, comminution and energy of the injury of bone that influence the choice of treatment.

Financial or Other, Competing Interest: None.

Submission 04-06-2016, Peer Review 03-07-2016,

Acceptance 11-07-2016, Published 26-07-2016.

Corresponding Author:

Dr. Sankara Rao Pinnamaneni,

Associate Professor,

Department of Orthopaedics,

MIMS Medical College, Nellimarla,

Vizianagaram-535217,

Andhra Pradesh.

E-mail: vpneni@yahoo.com

DOI: $10.14260 /$ jemds $/ 2016 / 1297$

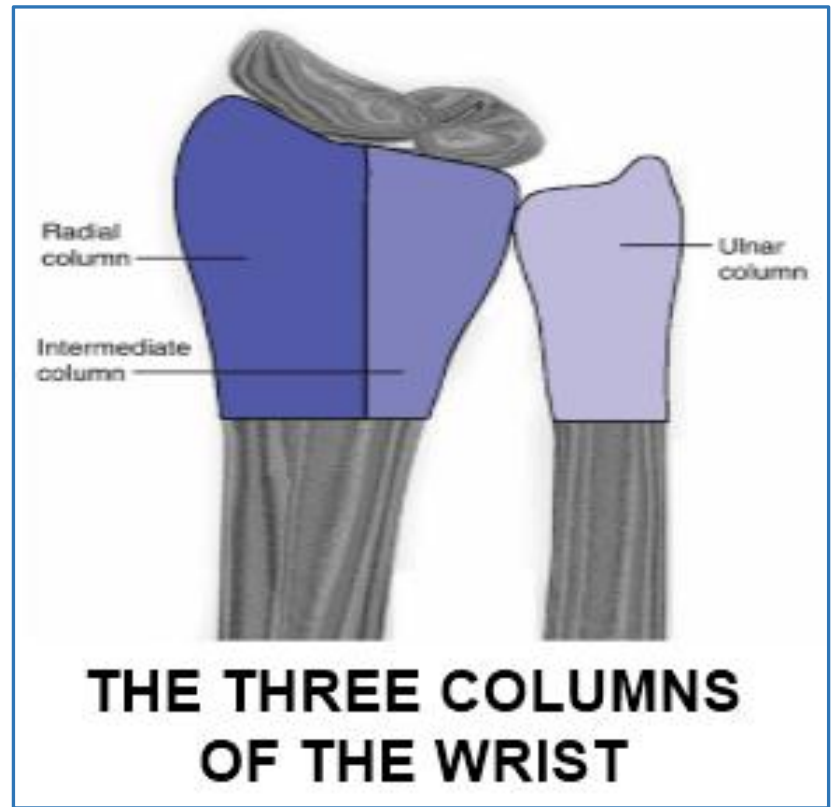




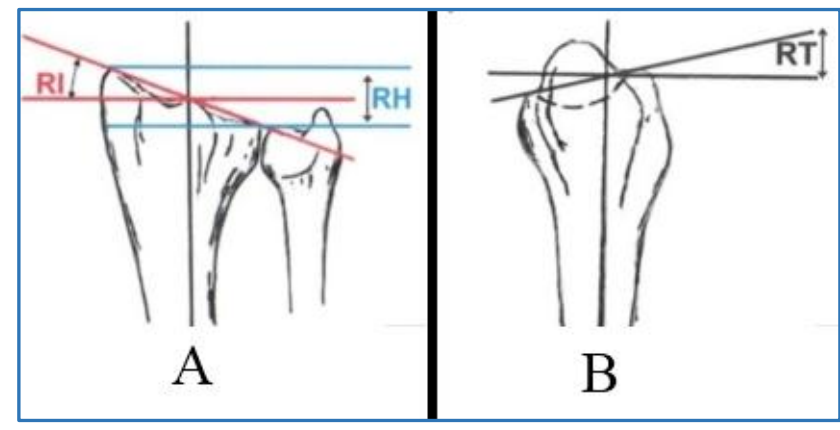

Radiographically, ${ }^{10}$ in AP view features a radial inclination of $22^{\circ}$, radial length of 9 to $12 \mathrm{~mm}$ and ulnar variance of $0 \mathrm{~mm}$. In lateral joint views, the distal radius shows a volar tilt of approximately $11^{\circ}$.

Illustrations showing the standard anatomic measurement of Radial Inclination (RI) and Radial Height (RH) (A) as well as Radial Tilt (RT) (B).

\section{AIMS AND OBJECTIVES}

1. To study the functional outcome of distal radial fractures in adults treated by various methods.

2. To identify different types of fractures of distal radius and their functional outcome.

3. To study the complications of various surgical procedures done for distal radial fractures.

\section{PATIENTS AND METHODS}

A prospective study conducted on sixty adult patients with distal radial fractures treated at Chalmeda Anand Rao Institute of Medical Sciences, Karimnagar, between May 2013 and August 2015 under the Department of Orthopaedics.

\section{Inclusion Criteria}

1. Adult patients with distal radial fractures.

2. Patient willing to participate.

\section{Exclusion Criteria}

1. Elderly patients and children.

2. Patients with neurovascular deficiency.

3. Compound injury.

4. Patients with pathological fractures.

\section{METHODS}

\section{Operative Technique}

The volar radial approach (FCR approach), which uses the interval between FCR and Radial artery.

Radial artery retracted radially with the brachioradialis. The FCR is retracted medially, Pronator quadratus incised from radial surface. Fractured fragments reduced temporarily held with K-wires and Ellis plate applied and fixed with screws. Pronator quadratus sutured and wound closed in layers.

Postoperatively, wound was inspected on $5^{\text {th }}$ day and sutures were removed on $10^{\text {th }}$ day. Regular follow-up was done at an interval of 6 weeks, 3 months, 6 months and 12 months, and results are evaluated using Demerit scoring system of Gartland and Werley. ${ }^{10}$

\section{RESULTS}

There were $42(70 \%)$ males and $18(30 \%)$ females between the age group of $22-60$ years; $40(66.6 \%)$ patients had right side involvement (Dominant wrist) and 20 (33.3\%) had left side involvement. The follow-up ranged from 5-12 months. The average age was 40.66 years with the fracture being more common in the $4^{\text {th }}$ and $5^{\text {th }}$ decades. Males were predominant with right wrist affection more than left. All fractures were either due to road traffic accidents or fall on the outstretched hand with road traffic accidents being more common of the two with different fracture patterns of both extra-articular and intra-articular type. The average duration from the date of injury to the date of surgery was 3.9 days. Surgery was delayed till the $10^{\text {th }}$ day in $2(3.33 \%)$ patients who had Hypertension and Diabetes Mellitus and associated fractures. The average age was 40.66 years with all the patients selected for the study were admitted and examined according to protocol.

\section{We followed Frykman's Classification}

\begin{tabular}{|c|c|c|}
\hline Type & No. of Cases & Percentage \\
\hline I & 22 & $36.6 \%$ \\
\hline II & 8 & $13.33 \%$ \\
\hline III & 6 & $10 \%$ \\
\hline IV & 4 & $6.66 \%$ \\
\hline V & 2 & $3.33 \%$ \\
\hline VI & 3 & $5 \%$ \\
\hline VII & 9 & $15 \%$ \\
\hline VIII & 6 & $10 \%$ \\
\hline \multicolumn{2}{|c|}{ Table 1: Type of Fracture (Frykman's Classification } \\
15)
\end{tabular}

Of the cases $22(36.6 \%)$ of the fractures were Type-I, 8 (13.33\%) of Type-II, $6(10 \%)$ of Type III, $4(6.66 \%)$ of Type IV, 2 (3.33\%) of Type V, 3 (5\%) of Type VI, 9 (15\%) of Type VII and $6(10 \%)$ of Type VIII.

of the 60 selected cases closed reduction, cast application done in 30 cases, closed reduction external fixation in 2 cases, closed reduction with $\mathrm{K}$-wire fixation in 5 cases. Open reduction and internal fixation with plating in 12 cases and closed reduction external fixation and K-wires in 11 cases.

In our study, 20 patients received ORIF with plating and plating with K-wire augmentation. Of them $12(60 \%)$ had excellent results, 7 (35\%) had good and 1 (5\%) had fair functional recovery. Patients treated by external fixator with or without pinning showed a less satisfactory result: $20 \%$ being good, $60 \%$ fair and $20 \%$ poor result. Patients with Kwire fixation $60 \%$ had good results and $40 \%$ had poor results.

\begin{tabular}{|c|c|c|c|c|c|c|}
\hline Series & $\begin{array}{c}\text { PoP } \\
\text { Casting }\end{array}$ & $\begin{array}{c}\text { Closed } \\
\text { Reduction } \\
\text { and } \\
\text { Percutaneous } \\
\text { Pinning }\end{array}$ & $\begin{array}{c}\text { Closed } \\
\text { Reduction } \\
\text { External } \\
\text { Fixation }\end{array}$ & $\begin{array}{c}\text { OR \& IF } \\
\text { with } \\
\text { Plating }\end{array}$ & $\begin{array}{c}\text { OR \& IF } \\
\text { with } \\
\text { Plating } \\
\text { +K- } \\
\text { wires }\end{array}$ & $\begin{array}{c}\text { Closed } \\
\text { Reduction } \\
\text { with } \\
\text { External } \\
\text { Fixator } \\
\text { +K-Wire }\end{array}$ \\
\hline $\begin{array}{c}\text { John K. } \\
\text { Bradway } \\
\text { et al11 }\end{array}$ & - & 0 & 0 & 69 & 0 & 31 \\
\hline $\begin{array}{c}\text { Vargaonkar } \\
\text { Gauresh } \\
\text { et al12 }\end{array}$ & $50 \%$ & 0 & $25 \%$ & $25 \%$ & 0 & 0 \\
\hline $\begin{array}{c}\text { Harish } \\
\text { Kapoor } \\
\text { et al13 }\end{array}$ & 37 & 0 & 0 & 32 & 0 & 31 \\
\hline $\begin{array}{c}\text { Pattana } \\
\text { Shetty } \\
\text { et al14 }\end{array}$ & -- & 0 & 0 & 100 & 0 & 0 \\
\hline $\begin{array}{c}\text { Present } \\
\text { Study }\end{array}$ & $50 \%$ & 8.33 & 3.33 & 20 & 13.33 & 5 \\
\hline \multicolumn{7}{|c|}{ Table 2: Types of Fixation } \\
\hline
\end{tabular}




\begin{tabular}{|c|c|c|c|c|}
\hline Series & Excellent & Good & Fair & Poor \\
\hline $\begin{array}{c}\text { John K. } \\
\text { Bradway et al }{ }^{11}\end{array}$ & 56 & 25 & 19 & 0 \\
\hline $\begin{array}{c}\text { Jesse B. } \\
\text { Jupiter et al } 15\end{array}$ & 63 & 20 & 17 & 0 \\
\hline $\begin{array}{c}\text { Pattana } \\
\text { Shetty et al }{ }^{14}\end{array}$ & 18.75 & 46.88 & 18.72 & 15.65 \\
\hline Present Study & 30 & 53.3 & 13.33 & 3.33 \\
\hline \multicolumn{5}{|c|}{ Table 3: Results } \\
\hline
\end{tabular}

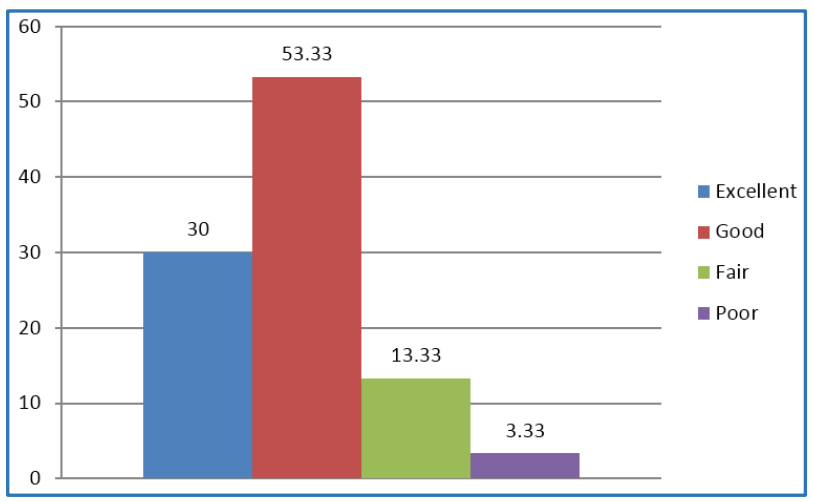

Graph 1: Observation and Results

\section{COMPLICATIONS}

Among the complications, malunion noticed in closed reduction with cast and stiffness of fingers. External fixation with K-wire noted finger stiffness in 2 cases, 1 case with pin track infection, while in open reduction with internal fixation with plating we have 1 superficial infection finger stiffness in 2 cases.

\section{POST-OPERATIVE FOLLOW-UP X-RAYS}

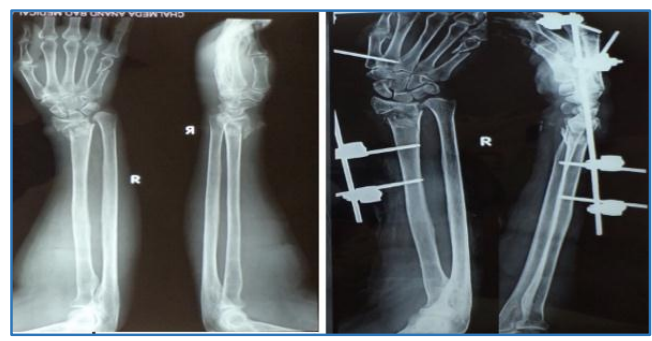

Immediate Post-Op

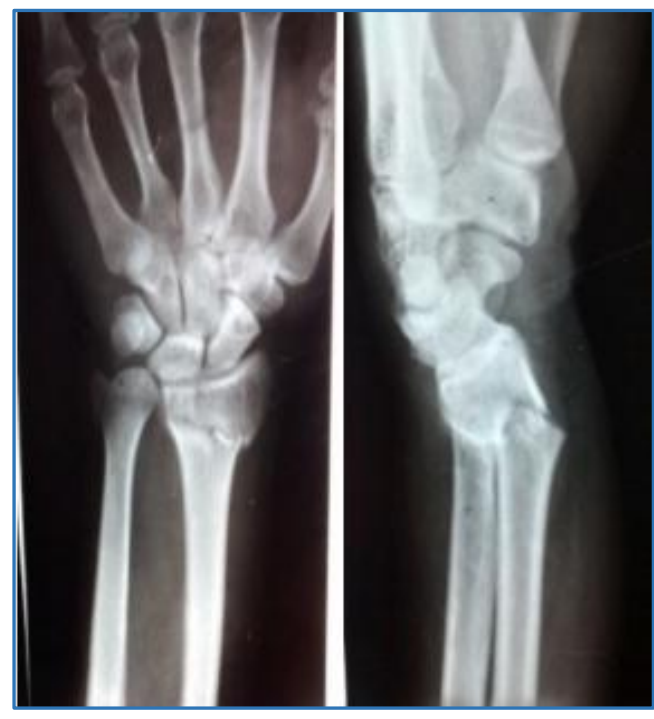

Pre-Op

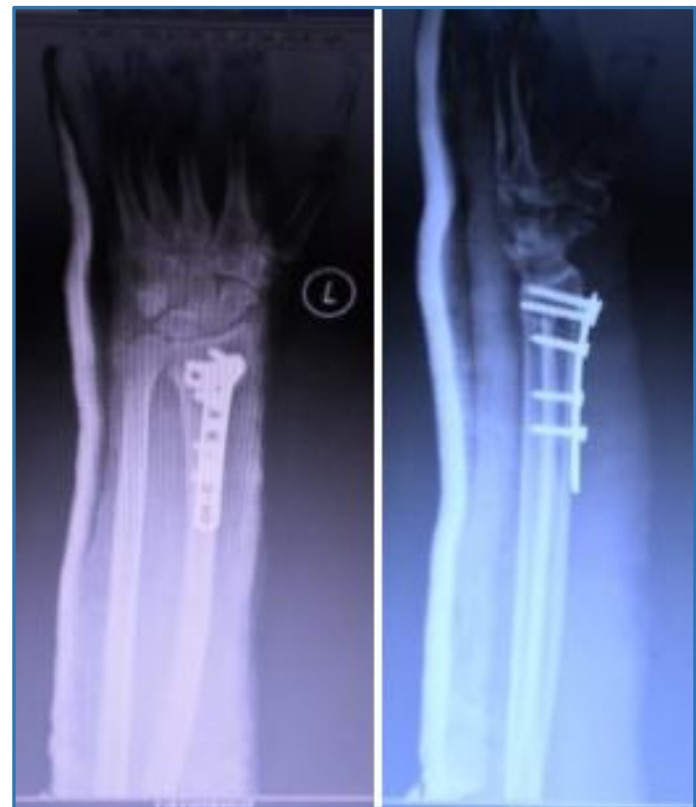

Immediate Post-Op

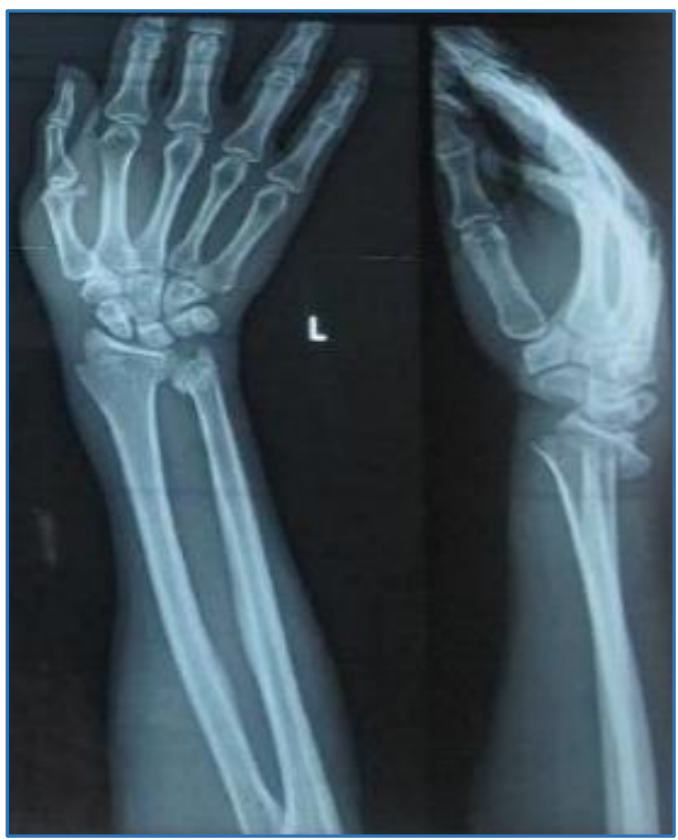

Pre-Op

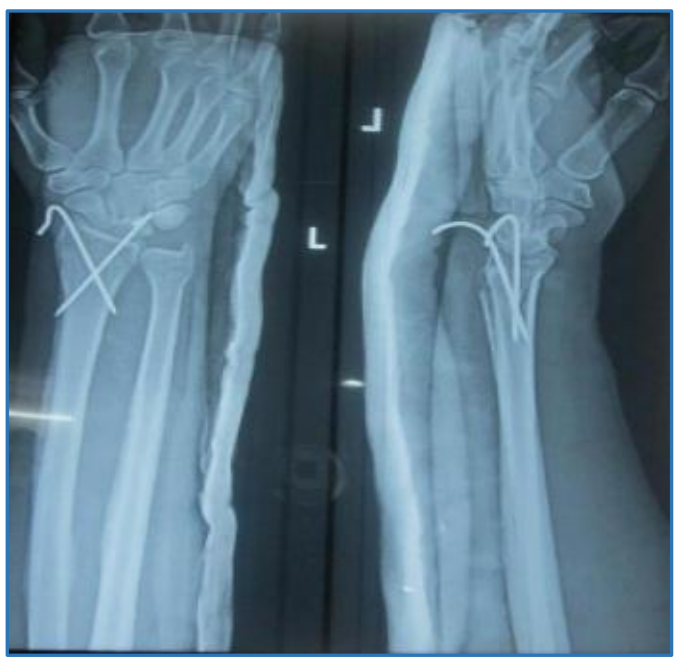

Immediate Post-Op 


\section{DISCUSSION}

The choice of particular operative method for each case should depend on the fracture pattern, reducibility, stability, quality of bone and patient requirement. Intervention is required in distal radius fractures to prevent complications and to improve functional outcome. Extra-articular fractures can be immobilised with POP casting, but with regular follow-ups.

Fractures with extreme comminution are best fixed with distraction and external fixation. Radial length, which is the most important radiological parameter is best maintained by external fixation due to sustained counter traction utilising the principle of ligamentotaxis. However, joint congruity and volar tilt may not be fully restored with external fixation.

Volar displaced fractures with subluxation or dislocation of the carpus on the radius (Volar Barton's) best treated by fixation with volar plate and screws. Open reduction and internal fixation provides the best chance for restoring joint congruity and therefore patients treated by this method have a lesser chance of developing secondary osteoarthritis.

Kirschner wires can be used for percutaneous pinning after closed reduction or to augment on external fixation to fix fragments too small for other means of fixation. They can also be used as 'joysticks' to control fracture fragments prior to internal fixation.

Operative treatment is a must for displaced intra-articular fracture to prevent the sequel of post-traumatic arthritis, pain and stiffness.

Intra-operative image intensification is a necessity for any operative method done to fix a distal radial fracture. Early fixation and early post-operative mobilisation and range of motion exercises greatly improve the long-term results. Regardless of the type of fixation, complication rates can be minimised by proper selection of implant and procedure, good surgical technique, proper pin site and wound care and fixation removal by 6 weeks in patients with external fixation and K-wires.

\section{CONCLUSION}

The choice of particular operative method for each case should depend on fracture pattern, reducibility, stability, quality of bone and patient requirement. Union is not the problem, as these fractures occur in the metaphyseal region. But malunion should be avoided by proper selection of implant and procedure, early reduction and fixation, better surgical skills.

\section{REFERENCES}

1. Colles A. On the fracture of the carpal extremity of the radius. Edinb Med Surg J 1814;10:181. Clin Orthop Relat Res 2006;445:5-7.
2. Thomas FB. Reduction of smith's fracture. J Bone Joint Surg Br 1957;39-B(3):463-70.

3. Bassett RL. Displaced intra-articular fractures of the distal radius. Clin Ortho 1987;214:148-52.

4. Cooney WP, Dobyns JH, Linscheid RL. Complications of colles' fractures. J Bone Joint Surg 1980;62(4):613-9.

5. Ziran BH, Scheel M, Keith MW. Pin reduction and fixation of volar fracture fragments of distal radius fractures via the flexor carpi radialis tendon. J Trauma 2000;49(3):433-9.

6. Jakob M, Rikli DA, Regazzoni P. Fracutures of the distal radius treated by internal fixation and early function. A prospective study f 73 consecutive patients. J Bone and Joint Surg 2000;82(3):340-4.

7. Emami A, Mjoberg B. A safer pin position for external fixationof distal radial fractures. Injury 2000;31(9):74950.

8. Kaempffe FA, Walker KM. External fixation for distal radius fractures: effect of distraction on outcome. Clin Orthop 2000;1(380):220-5.

9. Bucholz RW, Heckman JD, Court-Brown C. Rockwood and green's fractures in adults. 6th ed. Lippincott Williams \& Wilkins 2006:1.

10. Goldfarb CA, Yin Y, Gilula LA, et al. Wrist fractures: what the clinician wants to know. Radiology 2001;219(1): 11-28.

11. Bradway JK, Amadio PC, Cooney WP. Open reduction and internal fixation of displaced, comminuted intra-articular fractures of the distal end of the radius. J Bone Joint Surg 1989;71(6):839-47.

12. Gauresh V. Distal end radius fractures: evaluation of results of various treatments and assessment of treatment choice. Chinese Journal of Traumatology 2014;17(4):214-9.

13. Kapoor H, Agarwal A, Dhaon BK. Displaced intra-articular fractures of distal radius: a comparative evaluation of results following closed reduction, external fixation and open reduction with internal fixation. Injury 2000; 31(2): 75-9.

14. Shetty POB, Bhavi S, Bami M, et al. Outcome of fracture distal end of radius in adults treated by open reduction and internal fixation with buttress plate. Kerala Journal of Orthopaedics 2013;26(2):87-92.

15. Jupiter JB, Fernandex DL, Toh CL, et al. Operative treatment of volar intra-articular fractures of the distal end of the radius. J Bone Joint Surg Am 1996;78(12): 1817-28. 